\title{
OPTIMIZING THE PLANNING AND MANUFACTURING PROCESSES OF ELECTROMAGNETIC ENERGY HARVESTING EQUIPMENT
}

\author{
LÁSZLÓ MÓRICZ*1 AND ISTVÁN SZALAI ${ }^{1}$ \\ ${ }^{1}$ Institute of Mechatronics Engineering and Research, Faculty of Engineering, University of Pannonia, \\ Gasparich Márk u. 18/A, Zalaegerszeg, 8900, HUNGARY
}

\begin{abstract}
The main aim of this paper is to create an energy harvesting system, which can convert vibrational energy into electrical energy efficiently. Our research was carried out in the field of electromagnetic energy conversion using the principles of linear generator construction for both low and high frequency vibrations. Energy can be recovered efficiently. During the measurements, how the induced voltage is dependent on the impulsive frequency and the amplitude of impulses was investigated.
\end{abstract}

Keywords: energy harvesting, induced voltage, vibration, linear generator, energy

\section{Introduction}

Many forms of energy sources exist (vibrational, thermal, wind) in the environment which can be converted into electrical energy with a good degree of efficiency. The harvesting of this energy from the environment has the potential to reduce the rate of depletion of non-renewable energy sources [1] and can be converted by using electromagnetic $[2,3]$, electrostatic $[4,5]$ and piezoelectric $[6,7]$ energy conversion processes.

Our research was conducted in the field of electromagnetic energy conversion for both low and high frequency vibrations. Numerous energy harvesting mechanisms are based on the damped driven harmonic oscillator (DDHO) [8]. The essence of the process is to create relative displacement between a permanent magnet and a coil [9]. Electric power (energy) is induced in the coil due to changes in magnetic flux. To achieve the relative displacement, the magnet and leading house must come into physical contact which can be achieved mechanically or magnetically [10].

Each mechanical system has a mechanical damping factor. If the damping of the system is too low, the device exhibits no resistance to harmonic motion. However, if the value becomes too high, the resistance of the device to motion increases dramatically, thus no relative displacement of the device occurs. Both the damping force and relative displacement are essential to convert energy efficiently into the system [11].

One of the most difficult tasks of the design process is to define the appropriate degree of damping that maximizes the extractable efficiency. An important aspect of

\footnotetext{
*Correspondence: moricz.laszlo@mk.uni-pannon.hu
}

the design process is the tuning of the natural frequency of the structure. If the impulsive frequency deviates from the resonant frequency, a loss of power can be detected.

One possibility is that the bandwidth of operation is enhanced which results in the value of the "Quality (Q) factor" decreasing and diminishes the amount of extractable energy [5]. To achieve a good degree of efficiency of the system, the harvesting of very low frequency vibrations must be taken into account.

Regarding energy harvesting systems for low frequency applications, the possibilities of frequency upconversion are introduced and achieved in different ways. Ashraf et al. [11] optimized the mechanical design of the system by applying the Finite Element Method to broaden the low frequency range.

Haroun et al. [9] tried to keep the natural frequency of their system, namely CEH, low. They concluded that if the spring is not fixed to the moving frame (FIEH), then the natural frequency of the system is lower than that of the fixed spring system $(\mathrm{CEH})$.

\section{Design process and evolution of the structure}

There are two types of generator-based energy harvesting systems:

- System 1: based on linear movement

- System 2: based on rotational movement

The linear generator converts the mechanical movement directly into electrical energy. Several basic construction solutions can achieve this, e.g. the linear motors can 


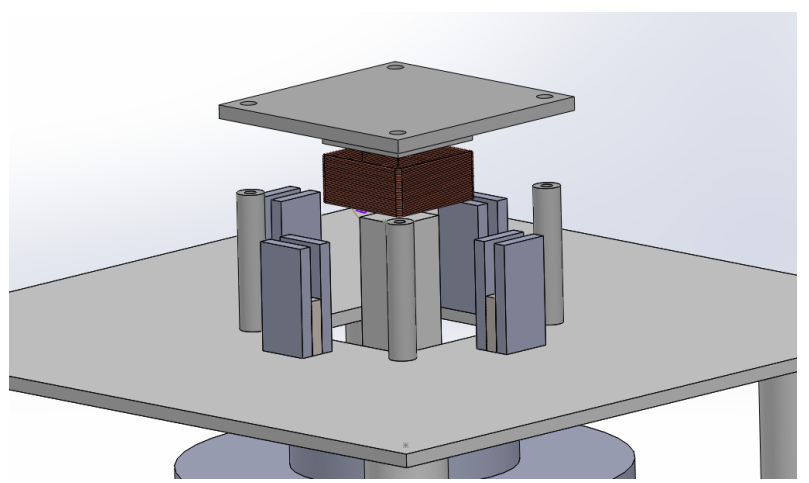

Figure 1: Mechanical structure of the EH system

be straightened versions of permanent magnet motors. The structure chosen is presented in Fig. 1. The energy harvesting model was made using SOLIDWORKS 2016 software. The assembled system is shown in Fig. 2.

The structure consists of two main parts; the stationary part possesses a coil holder and the moving part was produced from a square section slip. Four horseshoe neodymium magnets were mounted on the moving part. The horseshoe magnets consisted of two iron plates and a square neodymium magnet.

The thickness of the two iron plates was equal to that of the square neodymium magnet. It is important that the iron plate contains less alloys. The best solution from the options available was to use an iron core of a transformer.

To determine the optimum layout of the magnets, the direction of the current vectors (E) must be identical. As the direction of movement of the structure was definite $(\mathrm{v})$, according to the right-hand rule the direction of the magnetic induction vectors $(\mathbf{B})$ must point to the center as shown in Fig. 3.

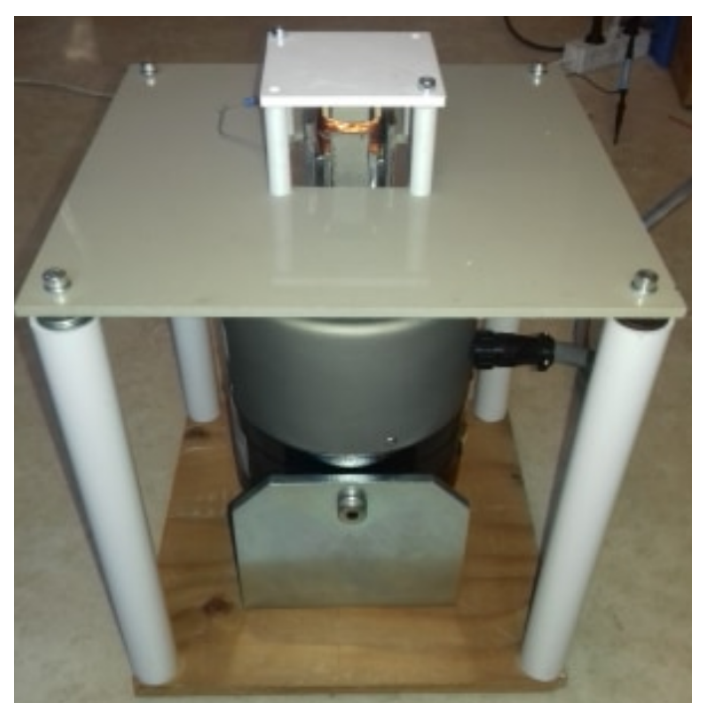

Figure 2: The assembled system

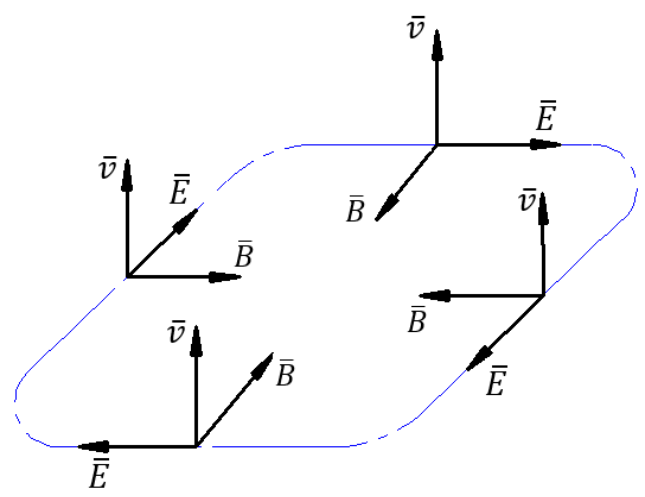

Figure 3: Optimum layout of the magnets

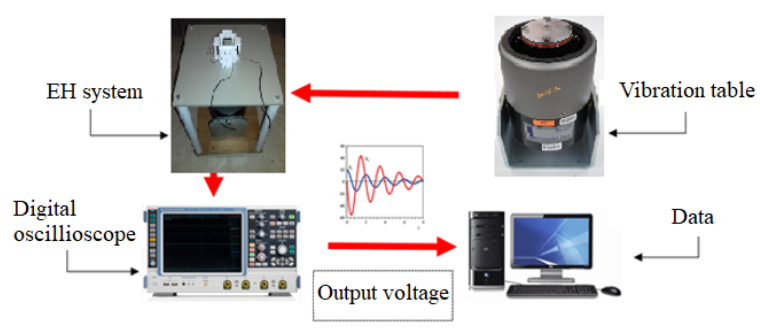

Figure 4: Schematic structure of the loop test

\section{Structure of the loop test}

The equipment for the loop test was provided by the Institute of Mechatronics Engineering and Research of the University of Pannonia in Zalaegerszeg. The schematic structure of the loop test is shown in Fig. 4.

Energy harvesting was executed by a type of Labworks ET-139 electrodynamic shaker. The induced voltage was displayed by an Agilent DSO5054A digital oscilloscope. The examined parameters were changed by a function generator, which was connected to a Labworks PA-138 amplifier on a vibration table as illustrated in Fig. 5.

\section{Results and Analysis}

\subsection{Based on experiments}

Throughout the experiments, the following attributes were examined:

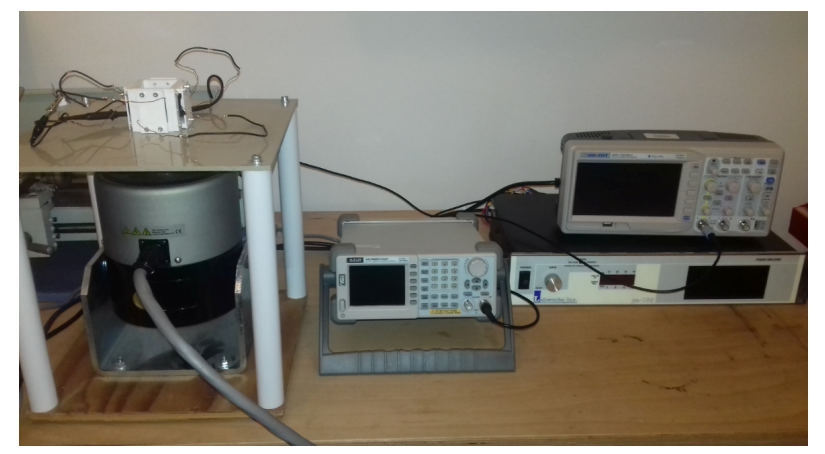

Figure 5: The set-up of the loop test 


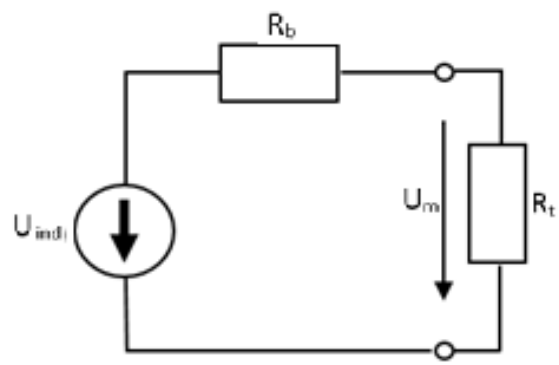

Figure 6: Energy-harvesting circuit diagram

- Maximum induced voltage without load

- Power without load

- Load on the power

- The impact of the number of coils on the induced voltage and power

The examined energy-harvesting circuit diagram is shown in Fig. 6. The structure consists of an internal resistance $R_{\mathrm{b}}$ and an external resistance $R_{\mathrm{t}}$ (load).

$$
\begin{gathered}
P_{\text {total }}=\frac{U_{\text {ind }}^{2}}{R_{\text {total }}}=\frac{U_{\text {ind }}^{2}}{R_{\mathrm{b}}+R_{\mathrm{t}}} \\
U_{\mathrm{m}}=U_{\text {ind }} \frac{R_{\mathrm{t}}}{R_{\mathrm{t}}+R_{\mathrm{b}}}
\end{gathered}
$$

As a result of the impulsive frequency and amplitude of impulses, electrical energy was induced. The induced voltage was equal to the measured voltage in the absence of external resistance. Measured and induced voltages differed when the system was subjected to an external resistance. The relationship between them is described in Eq. 2. The maximum power can be determined from Eq. 1.

\subsection{Results}

Initially, the device was tested with 100 turns of the coil. The internal resistance of the coil was $3.1 \Omega$. The impulsive frequency was set between 1 and $20 \mathrm{~Hz}$ and the amplitude of impulses between 2.5 and $15 \mathrm{~mm}$. During

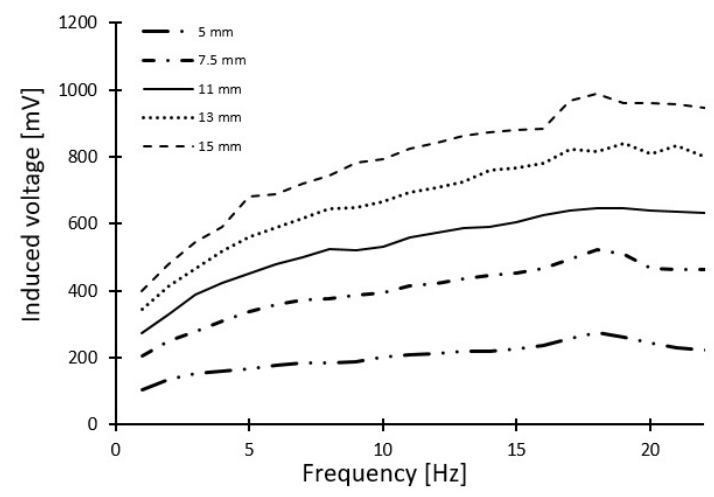

Figure 7: Induced voltage by applying 100 turns of the coil in the absence of external resistance

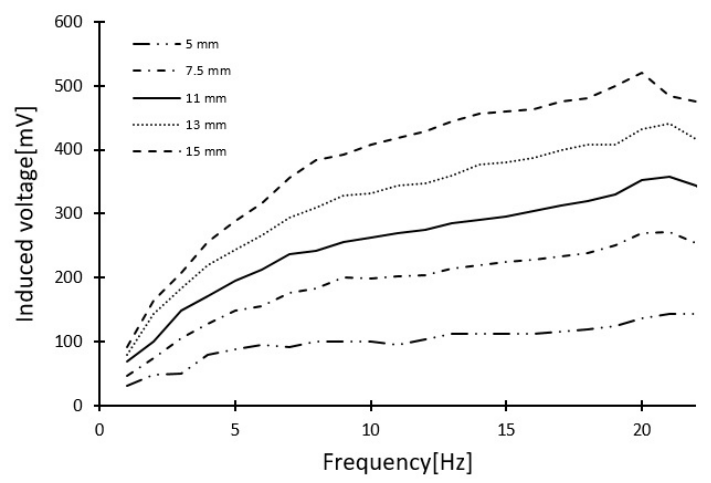

Figure 8: Induced voltage by applying 100 turns of the coil in the presence of an external resistance

the experiment, a decrease in the induced voltage was observed above $20 \mathrm{~Hz}$. Thus, the investigated bandwidth was maximized at $20 \mathrm{~Hz}$, whereas the trend was still visible in terms of the change in the curves, so 20 measurement points were examined during the experiments.

The results are summarized in Fig. 7. The maximum induced voltage and power were $986 \mathrm{mV}$ and $322 \mathrm{~mW}$, respectively.

During the experiments below, an internal resistance equal to the external resistance was applied to the structure. The applied external resistance was $3.4 \Omega$. The results are summarized in Fig. 8.

The maximum voltage measured was $520 \mathrm{mV}$. Given the values of the external and internal resistances, the induced voltage was $994 \mathrm{mV}$ based on Eq. 2. The maximum power was calculated to be $152 \mathrm{~mW}$ from Eq. 1 .

The impact of the external resistance on the power During the experiment, a constant excitation amplitude of $15 \mathrm{~mm}$ was applied, while the impact of the resistance on the power was examined. The resistances applied were $1,3.4,10,22,47$ and $74 \Omega$. The relationship between the changes in resistance and power are summarized in Fig. 9.

As is shown in Fig. 9, an exponential decrease in power was observed as the resistance increased. Based on previous studies, an external resistance that is smaller

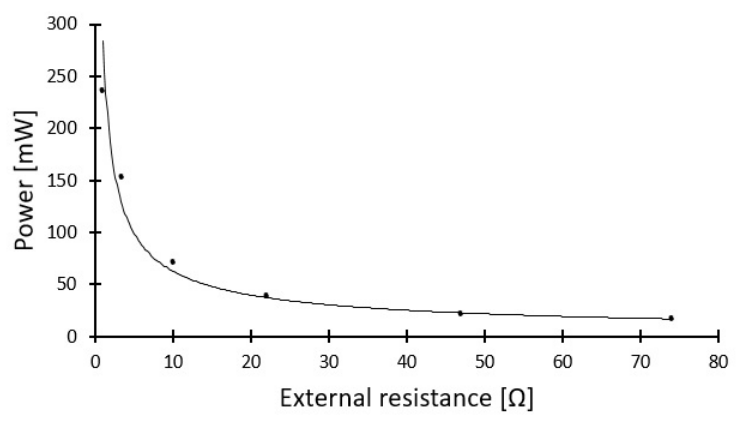

Figure 9: The relationship between the resistance and power 


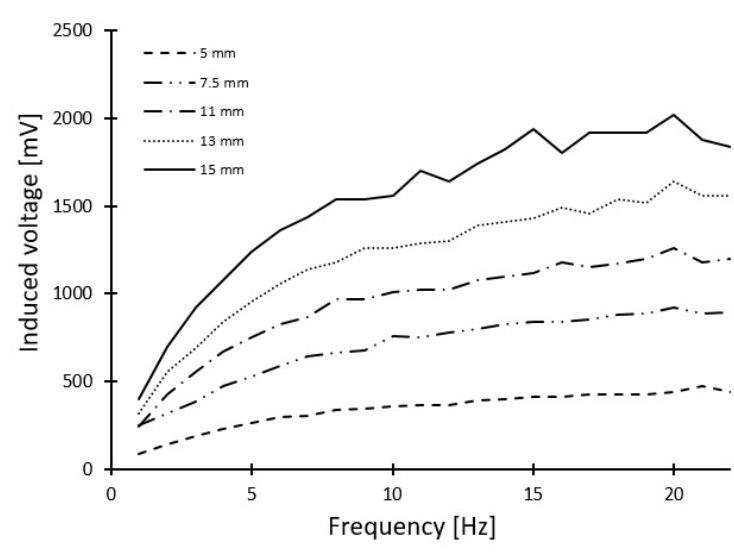

Figure 10: Induced voltage by applying 240 turns of the coil in the absence of an external resistance

than the internal resistance is impractical. Ideally, the external resistance would be equal to the internal resistance of the coil.

Next, the number of turns of the coil was increased from 100 to 240 . The other aforementioned variables remained unchanged. The results are summarized in Fig. 10.

As shown in Fig. 11, the maximum induced voltage without a load and the maximum power were $2020 \mathrm{mV}$ and $559 \mathrm{~mW}$, respectively. Following the aforementioned procedures, the loaded system was analyzed.

The external resistance applied was $8 \Omega$. The maximum voltage measured was $1060 \mathrm{mV}$. By taking into account the values of the external and internal resistances, the induced voltage was $2020 \mathrm{mV}$ based on Eq. 2. Based on Eq. 1, the maximum power calculated was $268 \mathrm{~mW}$. Both the induced voltage and power of the system were doubled by increasing the number of turns of the coil by $60 \%$, the induced voltage increased from $994 \mathrm{mV}$ to $2020 \mathrm{mV}$ and the maximum power rose from $152 \mathrm{~mW}$ to $268 \mathrm{~mW}$ to be exact.

\section{Discussion}

The aim of the research was based on the principles of linear generator construction and manufacturing. At this stage of the process, it was important that the structure was free of mechanical damping. During the experiment, the structure was examined by means of changing the load resistance and number of turns of the coil in addition to the specified amplitude and frequency. An exponential decrease in the efficiency was observed as the resistance increased. Ideally, the external resistance would be equal to the internal resistance of the coil. The induced voltage and the power of the system were doubled by increasing the number of turns of the coil by $60 \%$. As a result, by increasing the number of turns of the coil by $60 \%$, the efficiency of the system also increased by approximately $57 \%$. However, a deeper understanding of the relationship between the efficiency of the structure and variables

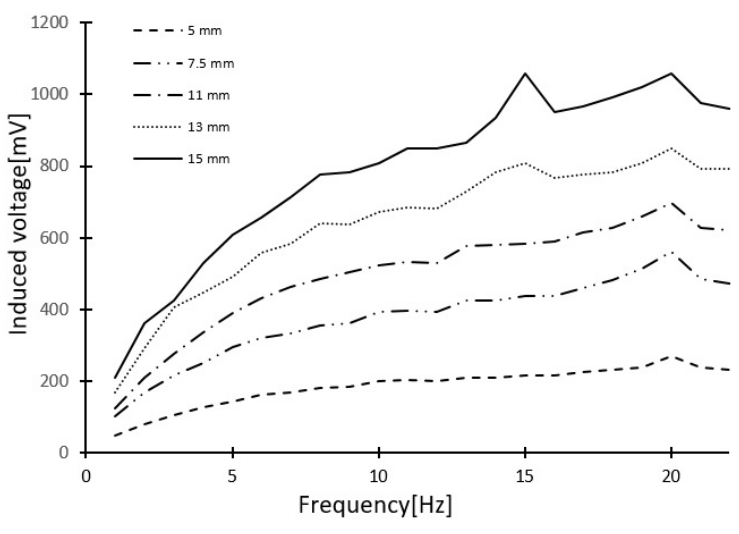

Figure 11: Induced voltage by applying 240 turns of the coil in the presence of an external resistance

requires further investigation. After doubling the number of turns of the coil, the maximum power generated was $1 \mathrm{~W}$. One advantage of this system in particular is that the neodymium magnets are cheap to produce. Applying a series connection to this system results in a sufficient degree of efficiency to operate the electronic devices in cars.

\section{Conclusion}

In the aforementioned experiments, the maximum induced voltage and power achieved by applying 240 turns of the coil were $2020 \mathrm{mV}$ and $559 \mathrm{~mW}$, respectively. During the experiments in the presence of a load resistance, the best value of the power was calculated when the external resistance was equal to the internal resistance of the coil. The efficiency of this energy harvesting system can be further enhanced by increasing the number of turns of the coil and the strength of the neodymium magnet.

\section{Symbols}

$\begin{array}{ll}U_{\text {ind }} & \text { induced voltage } \\ U_{\mathrm{m}} & \text { measured voltage } \\ P_{\text {total }} & \text { power } \\ R_{\mathrm{b}} & \text { internal resistance } \\ R_{\mathrm{t}} & \text { external resistance }\end{array}$

\section{Acknowledgements}

The project was supported by the European Union and co-financed by the European Social Fund through the project EFOP-3.6.2-16-2017-00002.

\section{REFERENCES}

[1] Elmes, J.; Gaydarzhiev, V.; Mensah, A.; Rustom, K.; Shen, J.; Batarseh, I.: Maximum Energy Harvesting Control for Oscillating Energy Harvesting Systems, 2007 IEEE Power Electronics Specialists Conference, 2007 DOI: 10.1109/pesc.2007.4342461 
[2] von Büren, T.; Tröster, G.: Design and optimization of a linear vibration-driven electromagnetic micropower generator, Sensor Actuat. A-Phys., 2007, 135(2), 765-775 DOI: 10.1016/j.sna.2006.08.009

[3] Beeby, S.P.; Torah, R.N.; Tudor, M.J.; GlynneJones, P.; O’Donnell, T.; Saha, C.R.; Roy, S.: Micro electromagnetic generator for vibration energy harvesting, J. Micromech. Microeng., 2007, 117(7), 1257-1265 DOI: 10.1088/0960-1317/17/7/007

[4] Mitcheson, P.D.; Green, T.C.: Maximum effectiveness of electrostatic energy harvesters when coupled to interface circuits, IEEE T. Circuits-I, 2012,59(12), 3098-3111 DOI: 10.1109/tcsi.2012.2206432

[5] Kiziroglou, M.E.; He, C.; Yeatman, E.M.: Electrostatic energy harvester with external proof mass, Proceedings of PowerMEMS, 2007, 117-120

[6] Marzencki, M.; Basrour, S.; Charlot, B.; Spirkovich, S.; Clin, M.: AMEMS piezoelectric vibration energy harvesting device, Proceedings of PowerMEMS, 2005, 45-48

[7] Isarakorn, D.; Briand, D.; Janphuang, P.; Sambri, A.; Gariglio, S.; Tricone, J. M.; Guy, F.; Reiner, J. W.; Ahn, C.H.; de Rooij, N. F.: Energy harvesting
MEMS device based on an epitaxial PZT thin film: fabrication and characterization, Technical Digest of PowerMEMS, 2010, 203-206

[8] Niu, P.; Chapman, P.: Design and Performance of Linear Biomechanical Energy Conversion Devices, (Power Electronics Specialists Conference, 2006. PESC '06. 37th IEEE), 2006, 1-6 DOI: 10.1109/PESC.2006.1711996

[9] Haroun, A.; Yamada,I.; Warisawa, S.: Study of electromagnetic vibration energy harvesting with free/impact motion for low frequency operation, J. Sound Vib., 2015, 349, 389-402 DOI: 10.1016/j.jsv.2015.03.048

[10] Móricz, L.; Szalai, I.: Mágneses lebegtetés elvén múködő vibrációs energiaátalakító tervezése és építése, (OGÉT 2019 XXVII. Nemzetközi Gépészeti Konferencia, Nagyvárad, Románia), 2019, 352-355

[11] Ashraf, K.; Md Khir, M.H.; Dennis, J.O.; Baharudin, Z.: Improved energy harvesting from low frequency vibrations by resonance amplification at multiple frequencies, Sensor Actuat. A-Phys., 2013, 195, 123-132 DOI: 10.1016/j.sna.2013.03.026 